\title{
Improving of the monolithic foamconcrete quality for used in the high-rise constructions
}

\author{
Anastasia Sychova ${ }^{1, *}$, Andrey Solomahin ${ }^{1}$, Vitaliy Kotovich ${ }^{1}$, Larisa $_{\text {Svatovskaya }}{ }^{2}$, and \\ Yuriy Kamenev ${ }^{1}$ \\ ${ }^{1}$ Military Space Academy named after A.F.Mozhaisky, 197198 Zhdanovskaya st.13, St.Petersburg, \\ Russia \\ ${ }^{4}$ Emperor Alexander I St. Petersburg State Transport University, 190031 Moskovsky pr.9, \\ St.Petersburg, Russia
}

\begin{abstract}
The article is devoted to the problem of obtaining the desired rheological characteristics of the foamconcrete when transporting it by the feeding pipelines to the place of installation in high-rise construction. The dependence of the density change of foamconcrete on the height to which it is transported is shown. It is stated that the use of stabilizers for the foam, as well as certain mechanisms of stabilization results in the concrete mix of the required density. To assess the rheological properties of the concrete mix the coefficient of volumetric relaxation is proposed.
\end{abstract}

\section{Introduction}

Interest in the use of monolithic non-autoclave foam concrete in walling and partitions of high-rise buildings is due to the fact that its application allows you:

-to simplify and reduce the cost of construction due to the production of the foam concrete on the construction site;

-to work year-round (in winter at temperatures down to $-15^{\circ} \mathrm{C}$ without the additional care of the concrete; the foamconcrete can accumulate heat due to the implementation of the thermos effect);

-to increase the volume of work more than ten times, in comparison with the laying of aerated concrete and foam concrete blocks, with a significant reduction in the number of workers;

-to minimize the use of crane and lifting equipment (the supply of monolithic foamconcrete is made from ground mark);

-to abandon the use of adhesive mortar and lintels, as in the case of manufacturing gas concrete masonry (to eliminate the "cold bridge");

-to reduce significantly the removal of debris from the construction site (breakage of gasaerated concrete blocks);

-to reduce transport expenses and the area of the zones of materials storage;

-to get the extra dwelling space by reducing the thickness of the thermal insulation of external walls by using foam concrete of low densities $[1,2]$.

\footnotetext{
*Corresponding author: amsychova@yandex.ru
} 
Practice shows that in constructing a sixteen-storey building with the perimeter of 400500 meters an additional dwelling space of $500 \mathrm{~m}^{2}$ is formed. It takes place due to the use of monolithic foam concrete with medium density of $300 \mathrm{~kg} / \mathrm{m}^{3}$ filled between the outer cladding walling in a half-brick and its inner lining-water-resistant gypsum board (Fig.1).

The possible applications of heat-insulating of monolithic foam concrete with medium density of $300 \mathrm{~kg} / \mathrm{m} 3$ in high-rise building are shown in Fig.1-3.

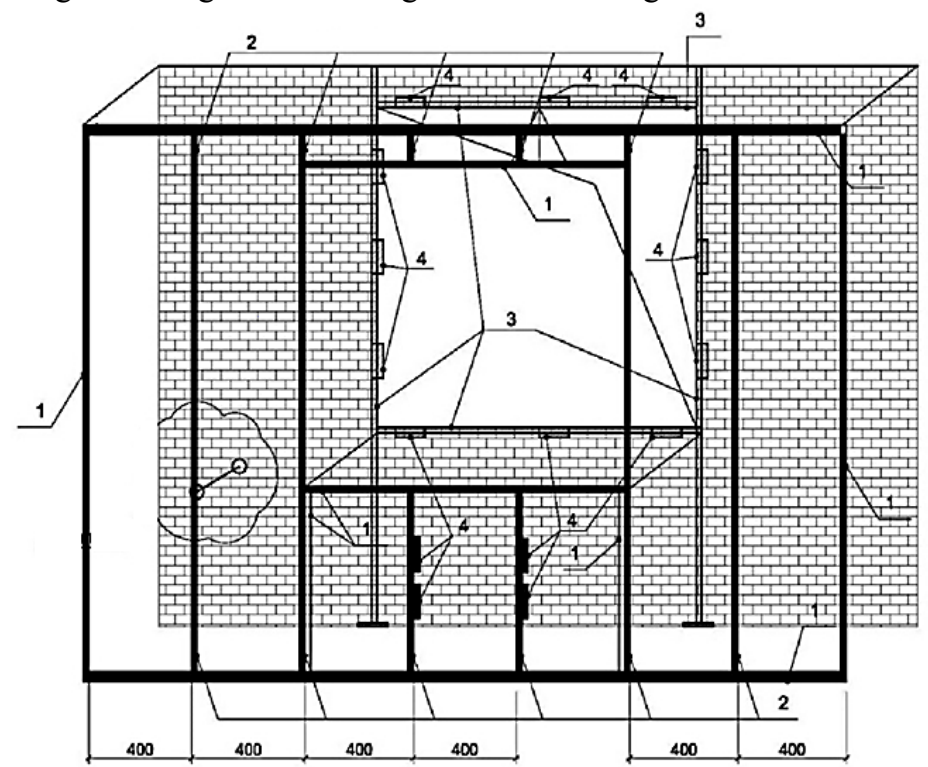

Fig.1. The construction of the outer walls of frame-monolithic building, in which the monolithic foam concrete is placed: 1 - guide profile $30 \times 27 \mathrm{Mm} ; 2$ - profile 60х27мм; 3 - profile 66x30мм; 4 - packing wood treated with anti-septic.

The construction of the outer wall of frame-monolithic building, in which the monolithic foam concrete is placed is shown in Fig.1.

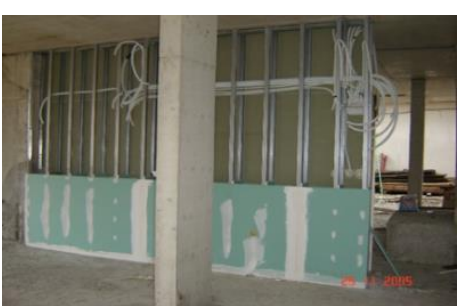

a

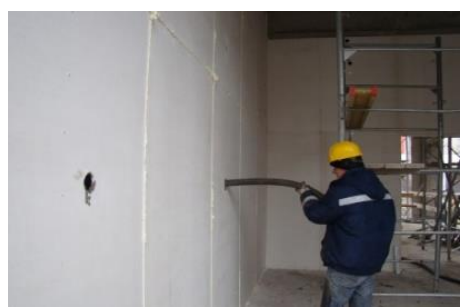

b

Fig.2. Internal partitions of the building with monolithic foamconcrete filler: a -frame construction of the interior walls, $\mathrm{b}-\mathrm{a}$ variant of the layer-by-layer pouring of foam concrete into the fixed formwork of the partition

The possible internal partitions of the building with using the monolithic foam concrete is shown in Fig.2. 




Fig. 3. The protecting constructions of the high-rise building with filling a foamconcrete into the fixed formwork.

Figure 3 shows a high-rise building, in which the foam concrete is poured into the fixed formwork, consisting both from the outer and inner side of the frame on the basis of light galvanized steel profiles of different cross-section. It can be sheathed from the outside, for example with cement-bonded plates with the subsequent finishing of the outer surface and with moisture-proof gypsum cardboard sheets inside.

In all the proposed schemes heat-insulating foamconcrete with its layer-by-layer placing into the structure is used. The layer height is up to $600 \mathrm{~mm}$.

The main feature of these technical solution application is the feeding technology of monolithic foam concrete from zero design level up to 70 meters vertically and up to 200 meters horizontally, in full compliance with the required design and rheological characteristics.

It is possible to realize it under the following conditions:

-first, only in the separate method of producing foam and water-cement-sand mixture with their further mixing in the common mixer;

- second, at the altitudes of above 20 meters, you must perform additional steps to increase foam stability;

-thirdly, due to the change in the scheme of foam supply to the height of over 20 meters without additional operations of improving the quality of the foam.

The change of feeding scheme means the transfer of foam concrete plant to the place of pouring, i.e. the breakdown of the building on the catches of the certain height takes place.

For monolithic foam concrete, the study of rheological properties is of great practical interest because they determine the behavior of foam-cement systems under stress when supplying to the place of pouring, its deformability and its ability to restore the original pore structure after load removal [3].

Nowadays the investigations of the problems of the rheological composition of the concrete mix change during transportation over long distances in the vertical were not undertaken. There are no systematic data about the critical height of feeding the foam concrete mixes of different rheological composition by using foam feeding equipment with different principles of work. Receiving, during transportation, the foam concrete with stable physico-mechanical characteristics is rather difficult.

Table 1 shows the values of changes in the density of foam concrete mix (for the average density D300 in a dry state) when feeding to the height from 0 to 70 meters.

The table shows that when feeding the foamconcrete to a height its density increases up to $50 \%$, and as a result, the foamconcrete does not meet the design brand and has a higher heat conductivity and lower thermal characteristics. 
Table 1. The change in the density of the foam concrete average density D300 depending on the delivery height

\begin{tabular}{|c|c|c|c|c|c|c|c|c|}
\hline \multirow{2}{*}{$\begin{array}{c}\text { The type of } \\
\text { foamconcrete }\end{array}$} & \multicolumn{7}{|c|}{ Feeding height, m } \\
\cline { 2 - 9 } & 0 & 10 & 20 & 30 & 40 & 50 & 60 & 70 \\
\cline { 2 - 8 } & 420 & 490 & 525 & 560 & 575 & 600 & 626 & 646 \\
\hline $\begin{array}{c}\text { Damp } \\
\text { foamconcrete } \\
\text { mixture }\end{array}$ & 300 & 370 & 400 & 440 & 455 & 480 & 500 & 520 \\
\hline $\begin{array}{c}\text { Foamconcrete } \\
\text { in the project } \\
\text { age }\end{array}$ & & & & & & & \\
\hline
\end{tabular}

To understand the processes of the concrete mix rheology change let us consider the scheme of its feeding by gerotor pump to the height of $\mathrm{H}$ and the resulting hydraulic pressure in the feeding line, Fig.4.

A column of the mixture $\mathrm{P}_{\text {mix }}$ (depending on the feeding height) as well as the starting pressure of the pump $\mathrm{P}_{\text {pump }}$ press on the bottom layer $\Delta \mathrm{H}$ of the foamconcrete mix.



Fig. 4. Diagram of the impact of different types of load on the bottom layers of foamconcrete during the vertical transportation

\section{Materials and Methods}

To assess the rheological stability of the concrete mix when transporting it to the building site at a considerable vertical distance, it was proposed to introduce the coefficient of volumetric relaxation of the foamconcrete mass, Kv.r. The value of this coefficient is proposed to be assessed as the ratio of the volume mass of the foam concrete mix at the outlet of the foamconcrete plant, $V m_{1}$ to the weight mass of the foamconcrete mixture at the outlet of the pipeline in the place pouring, $V m_{2}$, the formula 1:

$$
K v . r .=V m_{1} / V m_{2}
$$


From the formula we see that the higher Kv.r., the higher is the ability of the compound to perceive the various loads during the transportation without destroying. The dependence of the coefficient of volume relaxation upon the height of lifting the foamconcrete mix of the average density D300 is shown in Fig.5.

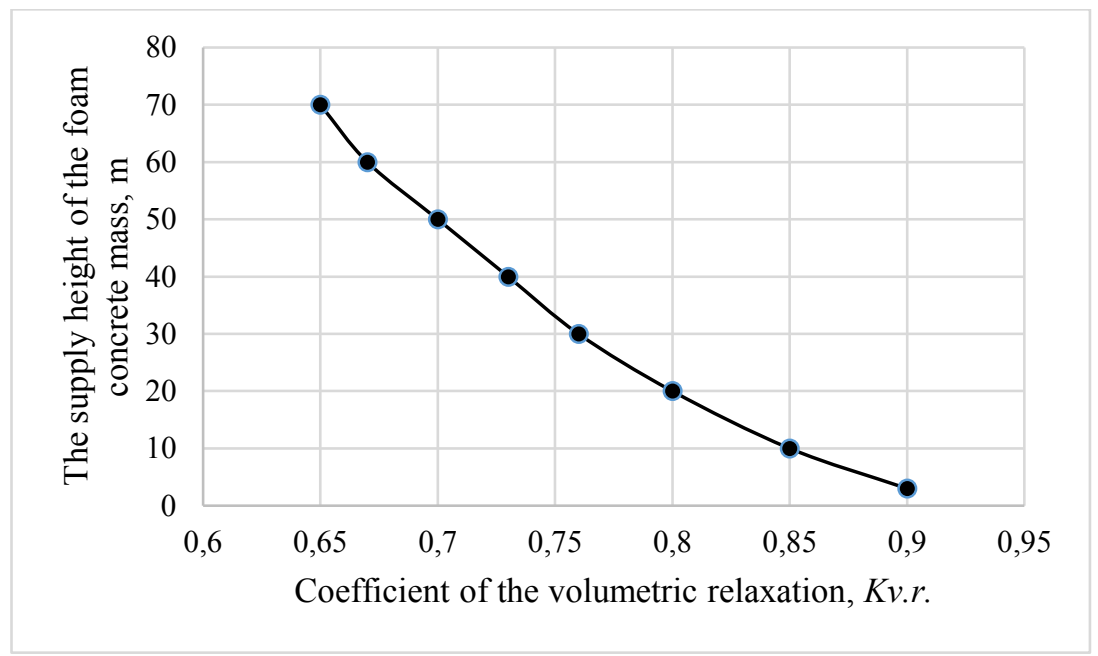

Fig. 5. The dependence of the coefficient of volumetric relaxation of the mixture upon the lifting height of the foam concrete mass

\section{Results}

The main idea of this work is the following assumption as the most "fragile element" in the concrete mix is a construction foam, its strengthening and stabilization should increase the Kv.r. of the foam concrete mix. This step should increase the stability of the concrete mix under different loads determined by the pressure in the pipeline and the height to which the mixture is lifted.

For experimental research a protein foaming agent was used, because it is the best from the point of view of its influence on the hydration of cement $[4,5,6]$.

The stabilizers providing a different mechanism for the stabilization of the foam were used. It's strength was estimated at the time of the stability in comparison with the control unstabilized foam [7]. Stability of the control foam was 40 minutes. The following agents were used as stabilizers: polyvinyl acetate; latex, $\mathrm{Fe}_{4}\left[\mathrm{Fe}(\mathrm{CN})_{6}\right]_{3}$ and $\mathrm{K}_{3}\left[\mathrm{Fe}(\mathrm{CN})_{6}\right][8$, 9]. Sols are colloid solutions that contain particles with a size $1-100 \mathrm{~nm}$ as a disperse phase $[10,11]$.

Experimental studies showed Fig. 6 that all the selected substances have a positive effect and increase the time of the foam stability up to 4.8 times. The best effect is when $\mathrm{K}_{3}\left[\mathrm{Fe}(\mathrm{CN})_{6}\right]$ was used. 




The concentration of polyvinyl acetate, $\%$

a

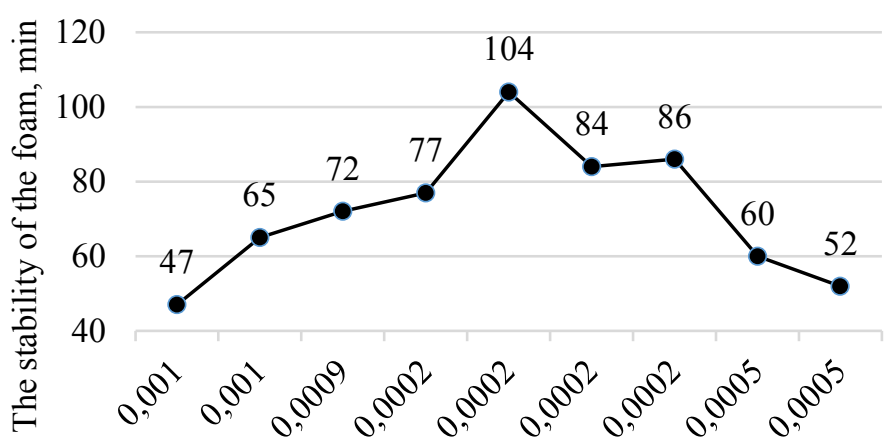

The concentration of latex, $\%$

b

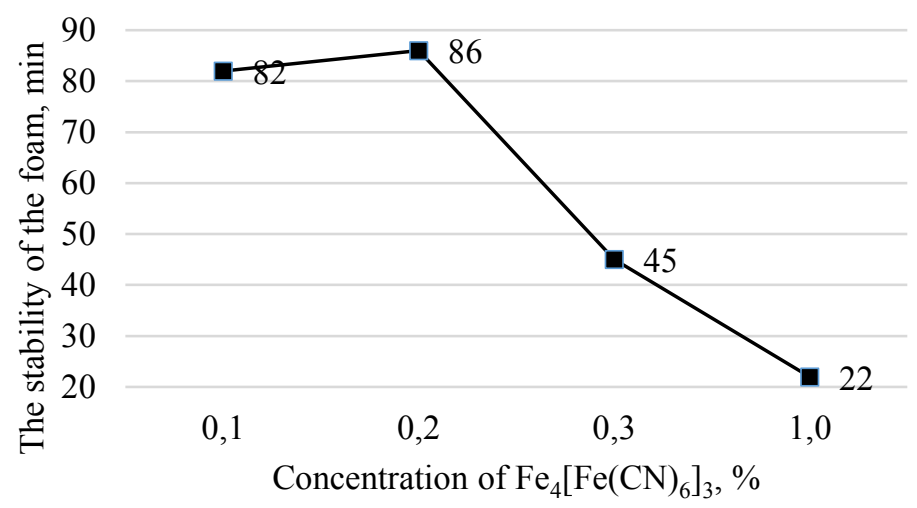

c 


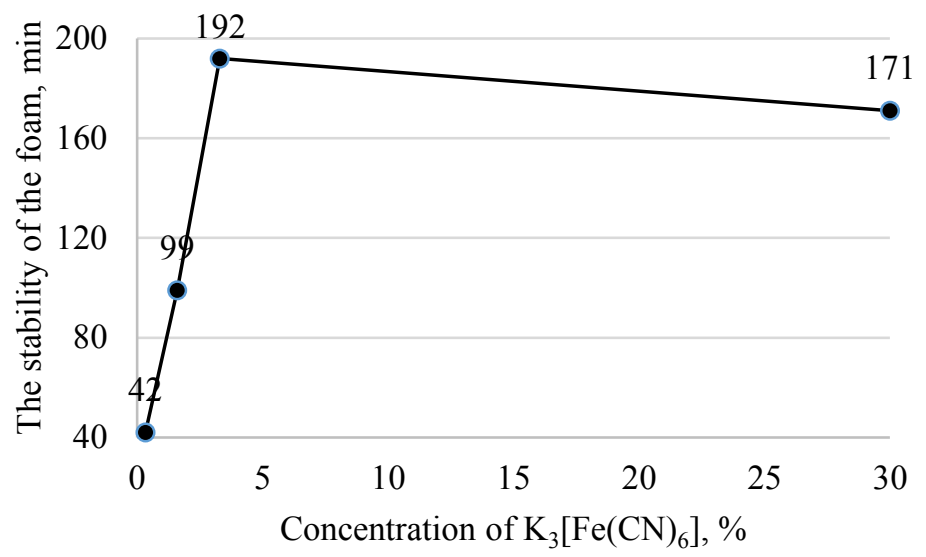

d

Fig. 6. Stability of the foam prepared on the basis of various stabilizers: $a$ - polyvinyl acetate; $b$ - latex; $\mathrm{c}-\mathrm{Fe}_{4}\left[\mathrm{Fe}(\mathrm{CN})_{6}\right]_{3} ; \mathrm{d}-\mathrm{K}_{3}\left[\mathrm{Fe}(\mathrm{CN})_{6}\right]$.

\section{Discussion}

The effect of the foam stabilization can be connected with the manifestation of two mechanisms. In the case of using polyvinyl acetate and latex the viscosity of the fluid foaming agent [12] increases, and in the case of $\mathrm{Fe}_{4}\left[\mathrm{Fe}(\mathrm{CN})_{6}\right]_{3}$ and $\mathrm{K}_{3}\left[\mathrm{Fe}(\mathrm{CN})_{6}\right]$ containing the ions $\mathrm{Fe}^{2+}$ and $\mathrm{Fe}^{3+}$, its interaction with protein molecules of the foaming agent is possible. This interaction formed a strong complex compounds, increasing the thickness of foam films [13]. In both cases, the stabilization effect results in the decrease in leakage speed of liquid from foam films under the action of gravity and increase the time of its sustainability.

It was further suggested that to maintain the rheology of the concrete mix when supplying it to the place of laying vertically not only the stability time, but also its structural and mechanical properties are important. Preliminary experiments showed that with the introduction of stabilizers based on iron ions strong, but fragile foam film is formed. It can't withstand hydraulic pressure in the pipeline during supply to the high altitude. In the case of using polymers that increase the viscosity of the liquid from foam films, the stability time of the foam is lower, but the foam has greater ductility, i.e. the ability to restore the shape of the bubble, and to relax after the action of the pressure in the pipeline [14, 15].

Fig. 7 shows the coefficient of volumetric relaxation of foamconcrete mixture prepared on the basis of the construction foam, stabilized with latex. From the figure it follows that the presence of the stabilizer increases the value of the Kv.r. up to $38 \%$ when supplying the foam to the height of $70 \mathrm{~m}$. 




Fig. 7. The dependence of the coefficient of volumetric relaxation of the lifting height of the foamconcrete mass prepared on the basis of the foam stabilized with latex.

When the height of a building is more than 70 meters it is recommended to use the method of laying foamconcrete by separating the building on the sections with a step of up to 70 meters and transfer the foam plant to the place of pouring. This method can provide the pouring of foam concrete mass in the process of buildings construction of any height.

\section{Conclusions}

1. It is propossed to assess the stability of wet foam concrete mass during transportation to the place of laying to the height of 70 meters by using the coefficient of volumetric relaxation, as the relationship of the density of the foam at the outlet from the foam plant to the density of the foam at the outlet from the pipeline.

2. For the first time it is proposed to increase the level of rheological properties of the of foam concrete during its transportation to the place of laying into the construction through the stabilization of foam and increase the strength of the foam bubble.

3. Foam stabilizers of different nature are considered and it is shown that the of foam stability in their presence increases up to 4.8 times; mechanisms of the stabilizing effect and their influence on structural and mechanical properties of the foam are proposed.

4. It is shown that by using foam stabilization, coefficient of volume relaxation of the foam concrete mass during its transport vertically up to 70 meters increases up to $38 \%$.

5. In the construction of buildings more than 70 meters height it is proposed to use the method of laying foamconcrete by separating the building on the section with a step of up to 70 meters and transfer the foam plant to the place of pouring.

\section{References}

1. V. Mikulski, V. Kupriyanov, Building materials (ASV, Moscow, 2000).

2. I. Rebjev, Building materials (Higher school, Moscow, 2003).

3. L. Shakhova, Technology of foam concrete. Theory and practice (Publishing house Association building universities, Moscow, 2010). 
4. L. Svatovskaya, M.Shershneva, M. Baidarashvili, N. Yakimova, A. Khitrov, Proceedings of the International Conference on Sustainable Waste Management and Recycling: Construction Demolition Waste, 199-203 (2004).

5. A. Sychova, M. Sychov, E. Rusanova, Procedia Engineering, 189, 681-687 (2017), DOI: $10.1016 /$ j.proeng.2017.05.108

6. L. Svatovskaya, A. Sakharova, M. Baidarashvilly, A. Petriaev, Proceedings of the 14th International Conference of International Association for Computer Methods and Recent Advances in Geomechanics, 152 (2014).

7. A. Sychova, A. Solomahin, A. Hitrov, Procedia Engineering, 189, 688-694 (2017), DOI: $10.1016 /$ j.proeng.2017.05.109

8. L. Svatovskaya, A. Kabanov, M. Sychov, IOP Conference Series: Earth and Environmental Science, 90, (2017), DOI: 10.1088/1755-1315/90/1/012010

9. A. Sychova, L. Svatovskaya, S. Mjakin, I. Vasiljeva, Electron Beam Modification of Solids: Mechanisms, Common Features and Promising Applications, 35-37, (2009).

10. A. Sychova, L. Svatovskaya, S. Mjakin, I. Vasiljeva, Electron Beam Modification of Solids: Mechanisms, Common Features and Promising Applications, 39-47, (2009).

11. A. Zimon, Colloid and surface chemistry (Agar, Moscow, 2007).

12. B. Summ D. Foundations of colloid chemistry (Academy, Moscow, 2007).

13. L. Shahova, V. Balyasnikov, Foam for cellular concrete (Belgorod, 2002).

14. N. Shabanova, Fundamentals of Sol-gel technology of nano silicon oxide (Akadembook, Moscow, 2004).

15. M. Gel'fman, N. Kirsanova, O. Kovalevich, L.Holohanowa, N. Rosalino, Workshop on colloid chemistry (Lan', Saint-Petersburg, 2005). 